First, the investigators patterned fuel channels of 80-90 $\mu \mathrm{m}$ depth by photolithography and wet etching a highly doped $\mathrm{Si}$ wafer. An $n$-type Si wafer was chosen because of its higher wet-etching rate with low resistivity to ensure it worked as a current collector. A $100 \mathrm{~nm}$ copper layer was sputtered on the Si wafer to supply current from a potentiostat. On the opposite side, anodization of the Si wafer in a $46 \%$ HFethanol solution using a current density of $100 \mathrm{~mA} / \mathrm{cm}^{2}$ resulted in a porous Si layer that grew up to the base of the fuel channels at a rate of $45 \mathrm{~nm} / \mathrm{s}$. These were the optimal conditions found for formation of a uniform porous Si layer. Anodizing typically lasted for 5-6 min, as observed experimentally. A catalyst layer was later deposited on the porous $\mathrm{Si}$ layer by using a plating bath of $1.0 \mathrm{M} \mathrm{H}_{2} \mathrm{SO}_{4}+10 \mathrm{mM}$ $\mathrm{H}_{2} \mathrm{PtCl}_{6}+5 \mathrm{mM} \mathrm{K}_{2} \mathrm{RuCl}_{5}+50 \mathrm{mM} \mathrm{HF}$ at $293 \mathrm{~K}$. The hydrofluoric acid added to the bath removed any silica present at any stage and resulted in electroless deposition of $\mathrm{Ru}$ and Pt. Thus, combining the HF addition to the bath with the use of a pulse plating technique assured the deposition of catalyst metal ions inside the pores of the catalyst layer. Otherwise, it was not possible to obtain coverage inside the pores since the catalyst metal ions were not able to reach the pores by electrodeposition means exclusively. The pulse plating technique utilized consisted of applying a current of $5 \mathrm{~mA} / \mathrm{cm}^{2}$ at a frequency of $1 \mathrm{~Hz}$ for $0.2 \mathrm{~s}$ followed by a halt of $0.8 \mathrm{~s}$. This cycle was repeated for $5 \mathrm{~min}$, obtaining coverage toward the porous Si layer to a depth of $10 \mu \mathrm{m}$. The Si wafer was then immersed in a $40 \% \mathrm{FeCl}_{2}$ solution at $313 \mathrm{~K}$ for 3-5 $\mathrm{min}$ to remove the copper layer. Two Si wafers thus processed were hot pressed with their catalyst sides facing top and bottom of a Nafion 112 piece, which worked as a polymer electrolyte membrane, using Nafion 5\% solution as an adhesive. Hot pressing was accomplished at $0.05 \mathrm{MPa}$ and $443 \mathrm{~K}$ for $30 \mathrm{~min}$. The total thickness of the miniature fuel cell thus assembled was $250 \mu \mathrm{m}$.

Testing the full assembly with hydrogen gas gave a peak power of $1.5 \mathrm{~mW} / \mathrm{cm}^{2}$ at $353 \mathrm{~K}$, and the porous Si layer indeed functioned as a current collector, reported the researchers. They said that the parabolic shape of the polarization curves show that the controlling mechanism is the catalyst performance. Power-generation capabilities of this miniature fuel cell are better than those of similar structure not using activated carbon as a catalyst layer, they said.

SIARI SOSA

\section{Electrochemical Polishing Technique Yields Apparatus for Manipulation of Micro- to Nanometer-Sized Magnetic Beads}

To date, the application of miniature electromagnets for molecular and cellular manipulation has been limited by weak magnetic field gradients and resultant weak magnetic forces that are produced by these devices. A further complication is resistive heating of the electromagnet that may damage living cells and lead to expansion of the material used for the electromagnet core. This thermally induced expansion diminishes the ability to control the level of applied force. For example, precisely controlled forces in excess of $100 \mathrm{pN}$ are required to produce nanometer-range displacements of a $4.5-\mu \mathrm{m}$ diameter magnetic microbead and the adhesion receptor on a living cell. B.D. Matthews of Harvard Medical School, D.A. LaVan of Yale University, and their colleagues have fabricated a temperature-controlled electromagnetic microneedle (EMN) capable of forces $>50 \mathrm{nN}$ with minimal heating.

As described in the October 4 issue of Applied Physics Letters (p. 2968), Matthews and co-workers have developed a novel electropolishing technique to create micromagnetic pole tips for controlled manipulation, probing, and positioning of magnetic particles. Their apparatus consists of multiple loops of insulated electromagnetic wire coiled around a permalloy magnetic core (1 mm diameter). Copper wire (50 $\mu \mathrm{m}$ diameter, 44 gauge) was wound around the magnetic core. Typical electromagnets in this study had 2000 turns of wire, a resistance of $16 \mathrm{Ohms}$, an inductance of $1.4 \mathrm{mH}$, and a capacitance of less than $2 \mathrm{pF}$. The core and electromagnet wires were housed within a temperature-regulated water flow chamber. Two 1-mm diameter plastic shields were fitted over the ends of the core, with an exposed section of the wire between them. The exposed end of the rod was initially electropolished in an 8:7:5 phosphoric acid, sulfuric acid, and water solution with an applied potential of $6 \mathrm{~V}$. After the core diameter was reduced by $50 \%$, the plastic shield was removed from the distal end of the rod and electropolishing continued at a $4 \mathrm{~V}$ applied potential until the distal end broke off. The final tip geometry was determined by the initial surface area exposed between the two plastic sleeves. Optical micrographs show that the technique is reproducible.

The researchers concluded that the magnitude of the magnetic field gradient generated by the EMN is primarily a function of the needle tip. EMNs with large tip radii $(20 \mu \mathrm{m})$ are capable of interacting with multiple beads, they said. Electropolishing to smaller radii $(0.1-6 \mu \mathrm{m})$ allows selective capturing of single magnetic beads. The researchers demonstrated removal of a single $4.5 \mu \mathrm{m}$ superparamagnetic bead from a group of similar ones, less than $10 \mu \mathrm{m}$ from each other. It is then possible, they said, to relocate the bead by moving the needle and simply shutting off the current. The researchers demonstrated that $50 \mathrm{nN}$ forces could be applied to $4.5 \mu \mathrm{m}$ diameter beads using an EMN with a pole tip radius of $20 \mu \mathrm{m}$, while more than $1 \mathrm{nN}$ could be applied to $250 \mathrm{~nm}$ diameter beads using an EMN with a pole tip radius of $100 \mathrm{~nm}$.

JEREMIAH T. ABIADE

\section{Bacteria Use "Molecular Lasso" to Cop Copper}

The bacteria that destroy about onethird of the potent greenhouse gas methane before it can reach the atmosphere produce a small organic compound and release it into the surrounding environment, where it "lassos" atoms of copper. The bacteria then reabsorb the compound and use the copper as a weapon against methane, from which they extract energy. The crystal structure of the compound, called methanobactin, is reported in the September 10 issue of Science (p. 1612). The research was led by H.J. Kim, who did much of the work as a graduate student at the University of Kansas and is now a postdoctoral associate at the University of Minnesota College of Biological Sciences. Methanobactin may have antibacterial properties, and its ability to absorb copper may find application in the semiconductor industry, which needs copper-free water.

The methanobactin molecule is a tiny, pyramid-shaped compound with a cleft that holds a single atom of copper in place. The researchers identified the components as a tetrapeptide, a tripeptide, and several moieties, including two 4-thionyl-5hydroxy-imidazole chromophores that coordinate the copper, a pyrrolidine that confers a bend in the overall chain, and an amino-terminal isopropylester group. The copper coordination environment, found at the base of the pyramid structure, includes a dual N- and S-donating system derived from the thionyl imidazolate moieties.

The bacteria that make methanobactin are common. "These bacteria are often found in rice paddies and wetlands," said Kim. "Methane is produced in the bottom muck and diffuses into the water, where these bacteria live. The bacteria sequester the methane and turn it into methyl alcohol." 